\title{
Improving power quality by calculating voltage losses
}

\author{
M. Borodin ${ }^{1, *}, A$. Psarev $^{1}, T$. Kudinova ${ }^{1}$, and R. Mukhametzhanov ${ }^{2}$ \\ ${ }^{1}$ Orel State Agrarian University named after N.V. Parakhin, Orel, Russia \\ ${ }^{2}$ Kazan State Power Engineering University, Kazan, Russia
}

\begin{abstract}
The problem of improving power quality (PQ) in the integrated power grid of Russia is an urgent task. The article analyzes the number of power consumers' calls to Kromskiye District Power Networks "Orelenergo", a branch of the PJSC "IDGC of the Center" for the issue that power quality indices go beyond the standards established in the regulations. The most common complaints of power consumers are low voltage, high voltage, voltage fluctuations. This is primarily due to physical and obsolete depreciation of the main power grid equipment of the power supply organization, disinterest of consumers and the power supply organization in maintaining power quality at the level of regulations, as well as the lack of power supply or-ganization's software products that allow real-time voltage loss calculations and offer measures to improve the power quality. The presented algorithm, based on calculations of voltage losses, suggests measures to improve the power quality. The application of the proposed algorithm of the program will allow to increase PQ by means of timely determination of voltage losses.
\end{abstract}

\section{Introduction}

According to the Civil Code of the Russian Federation, the electric power supplied to consumers must meet the requirements of state standards and power supply contracts. The responsibility of the power supply organization to consumers for the reliability of providing them with electric power and its quality, in accordance with technical regulations and other mandatory requirements, is defined in the "Federal Law on Electric Power Industry". According to [1-5], consumers need to be supplied with electric power of appropriate quality. Power quality (PQ) is one of the factors affecting the work of electrical receivers, switching devices, etc. The authors in [6-14] indicate that Russia has created a large number of regulations that establish requirements for $P Q$, but in practice they are not always effective. Distortion of power quality indices (PQI) leads to undersupply of products, changes in its parameters, reduction in the number of produced products, equipment downtime due to breakdowns, failure of switching equipment of power supply companies [1523 ], etc. Therefore, improving of PQ in power grids of power supply organizations is an urgent task.

\section{Research methodology}

The analysis of the number of electric power consumers' calls to the Kromskiye District Power Networks "Orelenergo", a branch of the PJSC "IDGC (Interregional Distribution Grid Company) of the Center" regarding the inconsistency of PQ with the guideline values was made, the results of the analysis are presented in Figure 1.

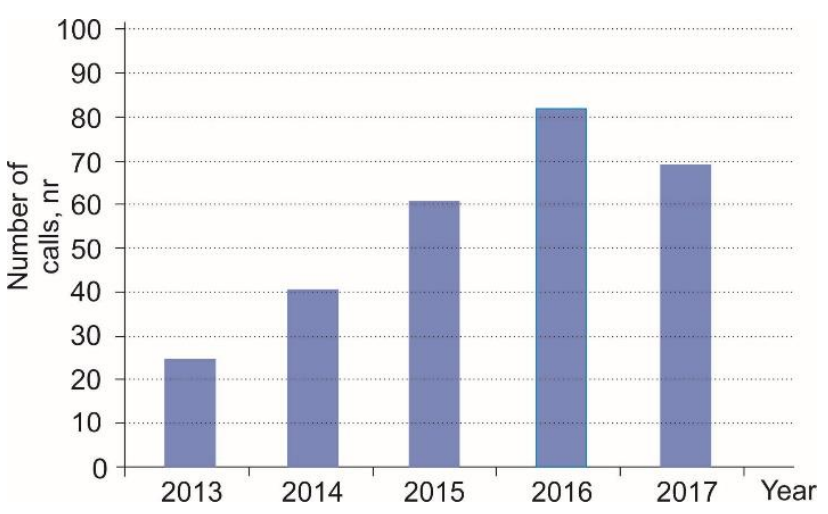

Fig. 1. The number of calls from consumers to the Kromskiye District Power Networksfor the in-consistency of power quality with guideline values.

The results presented in Figure 1 allow us to conclude that in the period from 2013 to 2017, the number of consumers' calls for the issue that power quality indices go beyond the guide line values was 246 , the largest number of calls was observed in 2016 and was equal to 82 . It is also necessary to note that the socalled "active consumers" usually apply for the inconsistency of PQ with the regulations.

The most common complaints of power consumers are low voltage, high voltage, voltage fluctuations. The number of calls for the above reasons is presented in Table 1.

\footnotetext{
Corresponding author: maksimka-borodin @yandex.ru
} 
Table 1. The number of calls from power consumers to the Kromskiye District Power Networks "Orelenergo", a branch of the PJSC "IDGC of the Center" in 2017-2018.

\begin{tabular}{|c|c|c|c|}
\hline \multicolumn{4}{|c|}{ Number of calls for2017-2018 } \\
\hline Low voltage & $\begin{array}{c}\text { Voltage } \\
\text { fluctuation }\end{array}$ & $\begin{array}{c}\text { High } \\
\text { voltage }\end{array}$ & Others \\
\hline 26 & 15 & 24 & 10 \\
\hline
\end{tabular}

Most consumers complain about voltage fluctuations. This is due to the fact that it is possible to visually determine the distortion of power quality only by the PQI distortion related to voltage distortion; at the same time, the electric grid company could prevent the power quality distortion by applying a set of measures aimed at improving the PQI related to voltage. A large number of consumers' calls for the inconsistency of PQ with regulatory levels are primarily related to the slow pace of the power grid recovery of the Kromskiye District Power Networks, as well as the lack of an effective program of improving power quality in $0.38 \mathrm{kV}$ power networks of the Kromskiye District Power Networks "Orelenergo", a branch of the PJSC "IDGC of the Center".

\section{Results and discussion}

In order to prevent consumers' complaints about the power quality distortion, the power supply company can determine the likely section with a power quality distortion; it isn't necessary to perform "global" analyzes, but simply enough to calculate electric power losses of existing transmission lines. It is also important to calculate the power loss, which is necessary for the feasibility study of future activities aimed at improving power quality.

The practical implementation of the above mentioned idea is presented below, while the calculations were made for some transmission lines of the Kromskiye District Power Networks "Orelenergo", a branch of the PJSC "IDGC of the Center".
Voltage losses were determined by the following formula:

$$
\Delta U=\frac{S_{r a t} \cdot\left(r_{0} \cdot \cos \varphi+x_{0} \cdot \sin \varphi\right) \cdot l}{U_{n}^{2}} \cdot 100 \%
$$

where $S_{\text {rat }}$ - load at the section of overhead lines, kVA (taken according to the power supply contracts); 1 length of the section, $\mathrm{km} ; \mathrm{U}_{\mathrm{n}}-$ nominal line voltage, $\mathrm{kV}$; $\mathrm{r}_{0}-$ resistivity of the wire, Ohm $/ \mathrm{km} ; \cos \varphi-$ power factor; $\mathrm{x}_{0}$ - inductive resistivity of the wire, $\mathrm{Ohm} / \mathrm{km}$.

The power loss for the year was determined by the expression:

$$
\Delta W=\frac{S_{r a t}^{2} \cdot \cos \varphi \cdot l \cdot \Delta U}{U_{n}^{2}} \cdot 100 \%
$$

The results of calculations of voltage losses and power losses in transmission lines of the Kromskiye District Power Networks are presented in Table 2.

The results of calculations show that the greatest voltage losses and deviations are observed at the Cabinet-type CTS-9-19 "Gorki", overhead line-0.4 kV, No. 2. The lowest voltage losses are observed at the Cabinet-type CTS-9-2 "Kotovka garages", overhead line- $0.4 \mathrm{kV}$, No. 2 and make up $1.69 \%$. The calculations show that voltage deviation is much more than the allowable value at the $85 \%$ of the CTS of the Kromskiye District Power Networks, this is primarily due to physical and obsolete depreciation of the main power grid equipment of the power supply organization, disinterest of consumers and the power supply organization in maintaining power quality at the level of regulations, as well as the lack of power supply organization's software products that allow real-time voltage loss calculations and offer measures to improve the power quality.

The authors have developed an algorithm that can be taken as the basis for a program that could, based on calculations of voltage losses, propose measures and make decisions to improve PQ. The algorithm of the program, that allows proposing measures to improve the

Table 2. Calculation results of voltage losses and power losses in some transmission lines of the Kromskiye District Power Networks.

\begin{tabular}{|l|c|c|c|}
\hline \multicolumn{1}{|c|}{ Complete Transformer Substation (CTS), No. } & $\Delta \mathbf{U}, \mathbf{\%}$ & $\Delta \mathbf{U}, \mathbf{V}$ & $\begin{array}{c}\Delta \mathbf{W}, \mathbf{k w} \\
\mathbf{k}\end{array}$ \\
\hline $\begin{array}{l}\text { Cabinet-type CTS-9-19 “Gorki” overhead line-0.4 } \\
\text { kVNo.1 }\end{array}$ & 29.64 & 112.84 & 2728.16933 \\
\hline $\begin{array}{l}\text { Cabinet-type CTS-9-19 “Gorki” } \\
\text { overhead line-0.4 kVNo.2 }\end{array}$ & 34.7 & 137.01 & 2691.69524 \\
\hline $\begin{array}{l}\text { Cabinet-type CTS-9-2 "Kotovka garages”, } \\
\text { overheadline-0.4 kVNo.1 }\end{array}$ & 12.12 & 6.42 & 1366.25241 \\
\hline $\begin{array}{l}\text { Cabinet-type CTS-9-2 “Kotovkagarages”,overheadline- } \\
\text { 0.4 kVNo.2 }\end{array}$ & 1.69 & 132.6 & 372.40304 \\
\hline $\begin{array}{l}\text { Cabinet-type CTS-9-4 "Kotovka Pole Transformer } \\
\text { Substation”, overheadline-0.4 kVNo.1 }\end{array}$ & 35 & 11.37 & 27268 \\
\hline $\begin{array}{l}\text { Cabinet-type CTS-9-4 ““Kotovka Pole Transformer } \\
\text { Substation”, overheadline-0.4kVNo.2 }\end{array}$ & 2.99 & 79.35 & 350.58864 \\
\hline $\begin{array}{l}\text { Cabinet-type CTS-9-3 "Kotovka”, } \\
\text { overhead line-0.4 kVNo.1 }\end{array}$ & 20.9 & 93.02 & 1639 \\
\hline $\begin{array}{l}\text { Cabinet-type CTS-9-3 “Kotovka”, } \\
\text { overhead line-0.4 kVNo.2 }\end{array}$ & 24.41 & 1913.62958 \\
\hline
\end{tabular}




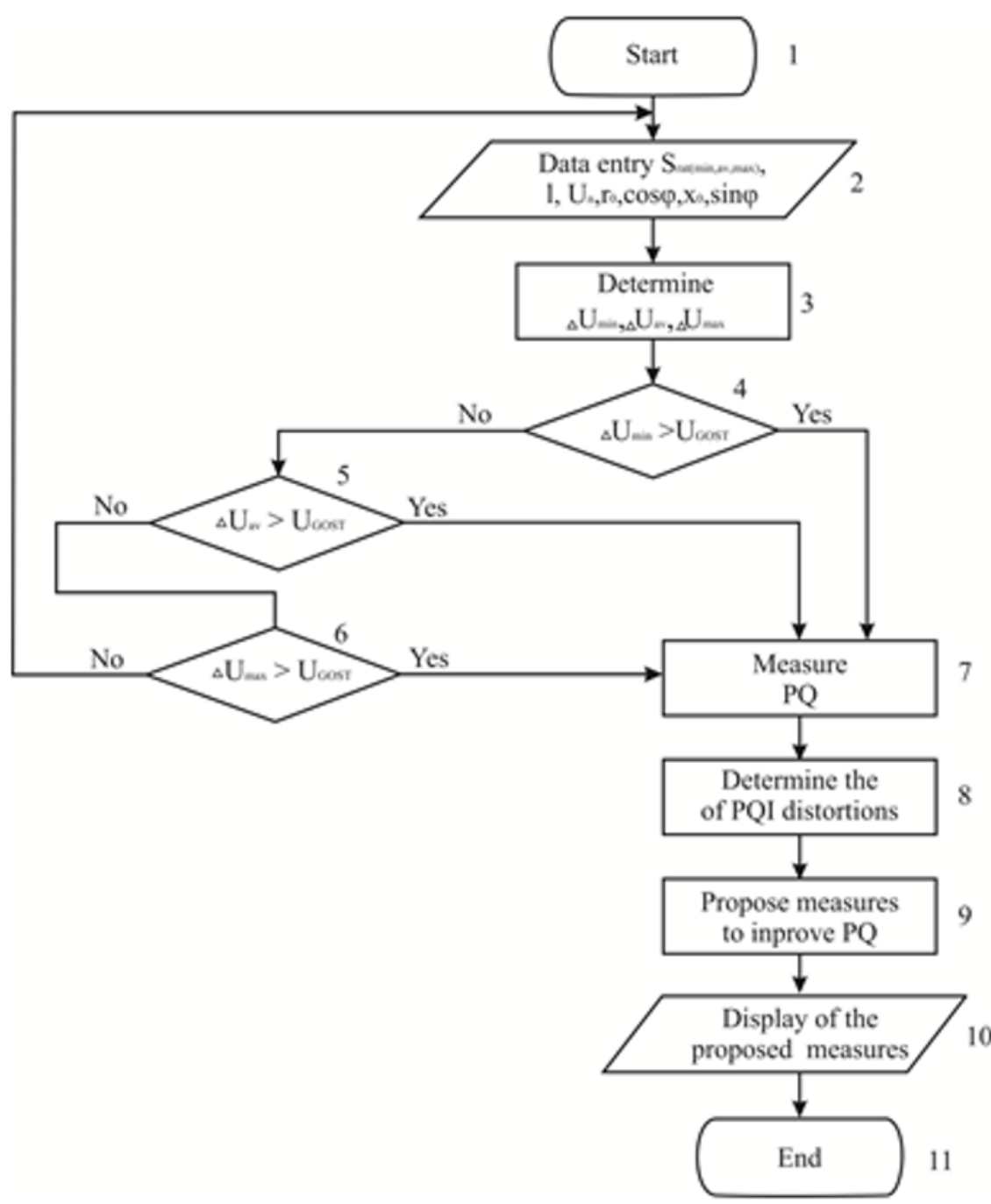

Fig. 2. The algorithm of the program that, on the basis of power loss calculations, proposes measures and makes decisions on improving PQ.

power quality, based on an analysis of the calculated voltage losses, is presented in Figure 2.

The beginning of the algorithm provides for data entry: the load at the section of overhead or cable lines, the length of the section, the nominal line voltage, the resistivity of the wire, the power factor, inductive resistivity of the wire. The specified data is updated each time a new calculation of power lines. Block 3 determines the voltage loss at the minimum, average and maximum loads of power lines. Blocks 4, 5, 6 perform the function of comparing the actual voltage loss with the guideline value. When voltage losses go beyond the guideline value Block 7 sends a signal to conduct PQ measurements. Next, block 8 determines the level of PQI distortion. Based on the number of PQI distortions that go beyond the guideline values and the regulatory level, measures are proposed to improve the power quality. Then, block 10 displays information about the proposed measures. Block 11 displays information about technical devices and organizational measures that will improve PQ.

This program can be applied as a stationary (installed on a computer, laptop, etc.), and in the implementation of "smart" networks. The use of the proposed program will allow to improve PQ by means of early (timely) determination of voltage losses, proposing measures aimed at improving $\mathrm{PQ}$.

\section{Conclusions}

Improving the power quality in the integrated power grid of Russia is an urgent task for power supply companies. To improve the power quality, an algorithm has been developed that can be used in a program that offers measures to improve the power quality, based on calculations of voltage losses. This program can be applied as a stationary (installed on a computer, laptop, etc.), and in the implementation of "smart" networks. The application of the proposed algorithm of the program will allow to improve PQ by means of early (timely) determination of voltage losses. 


\section{References}

[1] V.E. Bolshev, A.N. Vasilev, A.V. Vinogradov, A.E. Semenov, M.V. Borodin, Time factor for determination of power supply system efficiency of rural consumers Handbook of Research on Renewable Energy and Electric Resources for Sustainable Rural Development. Advances in Environmental Engineering and Green Technologie (Hershey: Pennsylvania) 394420 (2018)

[2] A. Vinogradov, V. Bolshev, A. Vinogradova, T. Kudinova, M. Borodin, A. Selezneva, N. Sorokin, A system for monitoring the number and duration of power outages and power quality in $0.38 \mathrm{kV}$ electrical networks Intelligent Computing \& Optimization.ICO, vol 866: 110In eds Vasant $P$ and Zelinka I and Weber G W (Springer, Cham) (2019)

[3] K. Bachmanova, Responsible for those who are connected Energy Without Borders 5(40), OctoberNovember 18-19 (2016)

[4] A.E. Semenov, Analysis of electric power losses in electric networks in the "Orelenergo" Livensky district power networks, a branch of the PJSC "IDGC of the Center" Innovative Development of the University Library: Management and Marketing. Materials of the 2nd Scientific Conf 68-71 (2018)

[5] P. Siano, Demand response and smart grids a survey Renewable and Sustainable Energy Reviews 30, 461- 78 (2014)

[6] A.V. Vinogradov, M.V. Borodin, A.V. Vinogradova, A.O. Selezneva, V.E. Bolshev, Monitoring system of power supply reliability and power quality in $0.38 \mathrm{kV}$ electrical networks Industrial Energy 3, 14-18 (2018)

[7] L. Fangxing, Q. Wei, S. Hongbin, W. Hui, W. Jianhui, X. Yan, X. Zhao, Z. Pei, Smart transmission grid: Vision and Framework IEEE Transactions on Smart Grid 1, 168- 77 (2010)

[8] V.A. Ovseychuk, Power reliability and quality to consumers.justification of the valuation Electrical Engineering News: Informational Reference Book / Founder CJSC "Electrical Engineering News" (St. Petersburg) 3(81), 50- 3 (2013)

[9] M.V. Borodin, A.V. Vinogradov, Adjustment of the consumed electric power cost depending on its quality Industrial energy 7, 12- 6 (2013)

[10] M.V. Borodin, A.V. Vinogradov, Adjustment of the consumed electric power cost depending on its quality Technique in Agriculture 5, 17-20 (2013)

[11] M.V. Borodin, A.I. Psarev, Assessment of the actual power quality and analysis of the number of calls for the inconsistency of power quality with guideline Values Agrotechnology and Power Supply 4(17), 54-63 (2017)

[12] A.V. Vinogradov, Borodin M.V., V. Bolshev, N. Makhiyanova, N. Hruntovich, Improving the power quality of rural consumers by means of electricity cost adjustment Renewable Energy Power Supply Challenges for Rural Regions. 312- 41

[13] M.V. Borodin, A.V. Vinogradov, Formulation of the methodology for adjusting the consumed electric power cost depending on its quality and algorithm of its implementation in accordance with GOST on power quality Bulletin of the Nizhniy Novgorod State Engineering and Economic Institute 4 (83), 54-64 (2018)

[14] M.V. Borodin, Power quality in the electrical facilities of the agro-industrial complex of the Livensky District of the Orel Region Resource-Saving Technologies for the Storage and Processing of Agricultural Products. Materials of the XIV Int. Scientific and Practical Workshop 157- 62 (2018)

[15] A.V. Vinogradov, Yu.I. Lukyanov, L.N. Shakina, Reducing the recovery time of power supply of rural consumers in case of failures in power lines Due to the use of partitioning and redundancy means Bulletin of the Kharkiv National Technical University of Agriculture named after Peter Vasilenko. Technical science. Issue 186 "Problems of Power Supply and Energy Saving in the Agricultural Sector of Ukraine." (Kharkov: KNTUA) 26-30 (2017)

[16] A.I. Psarev, Analysis of electric power losses in electric networks in the "Orelenergo" Orlovsky district power networks, a branch of the PJSC "IDGC of the Center" Innovative Development of the University Library: Management and Marketing. Materials of the 2nd Scientific Conf 65-8 (2018)

[17] R.P. Belikov, A.E. Semenov, I.N. Fomin, Methods and technical means of improving power quality in rural electrical networks Innovative Development of the University Library: Management and Marketing. Materials of the II Scientific Conf 60- 5 (2018)

[18] A. Yasin Kabalci, Survey on smart metering and smart grid communication Renewable and Sustainable Energy Reviews 57, 302- 18 (2016)

[19] I.O. Golikov, A.V. Vinogradov, Adaptive automatic voltage regulation in $0.38 \mathrm{kV}$ rural power grids Monograph (Orel: FSBEI HE Orel State Agrarian University named after N.V. Parakhin) 166 (2017)

[20] F.M. Cleveland, Cyber security issues for advanced metering infrastructure (AMI) IEEE Power and Energy Society General Meeting: Conversion and Delivery of Electrical Energy in the 21st Century 1-6 (2008)

[21] N.S. Sorokin, Improving the efficiency of functioning of electric networks with voltage of $6-35 \mathrm{kV}$ by monitoring the parameters of the electric network Scientific Bulletin of the National University of Bioresources and Environmental Management Ukraine. Series: Technique and Power Engineering of AgroIndustrial Complex 209-2, $92-5$ (2015)

[22] R.P. Belikov, Organizational and technical measures to improve the power quality Physics and Modern Technologies in the Agro-Industrial Complex. Materials of the X Int. Youth Conf. of Young Scientists, Students and Schoolchildren 38-41 (2019)

[23] E.A. Tsydenov, Yu.A. Zeremskaya, A.V. Chimrov, Methods of energy system statical stability improvement Journal of Economics and Social Sciences 10(10), 53-55 (2017) 